\title{
Dominance of individual plant species is more important than diversity in explaining plant biomass in the forest understorey
}

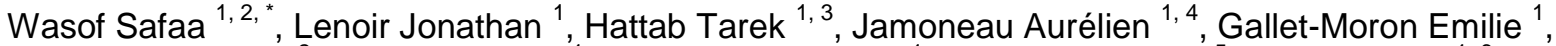 \\ Ampoorter Evy ${ }^{2}$, Saguez Robert ${ }^{1}$, Bennsadek Lamine ${ }^{1}$, Bertrand Romain ${ }^{5}$, Valdès Alicia ${ }^{1,6}$, \\ Verheyen Kris ${ }^{2}$, Decocq Guillaume ${ }^{1}$
}

${ }^{1}$ Unité de Recherche "Ecologie et Dynamique des Systèmes Anthropisés" (EDYSAN, UMR 7058),

Jules Verne University of Picardie; 1 rue des Louvels F-80037 Amiens Cedex 1, France

${ }^{2}$ Ghent University - Department of Forest and Water Management, Forest\& Nature Lab (ForNaLab);

Geraardsbergsesteenweg 267 B-9090 Gontrode, Belgium

${ }^{3}$ IFREMER UMR 248 MARBEC; Avenue Jean Monnet CS 3017134203 Sète Cedex ,France

${ }^{4}$ Unité de Recherche "Ecosystèmes aquatiques et changements globaux" (EABX), IRSTEA; 50 avenue de Verdun F-33612 Cestas, France

${ }^{5}$ CNRS, Centre for Biodiversity Theory and Modelling, Theoretical and Ecological Station, UMR 5321

CNRS; Paul Sabatier University; FR-09200 Moulis, France

${ }^{6}$ Department of Ecology, Environment and Plant Sciences; Stockholm University; Svante Arrhenius väg 20 A SE-106 91 Stockholm, Sweden

* Corresponding author : Safaa Wasof, email address : $\underline{\text { Safaa.wasof@ugent.be }}$

\begin{abstract}
:
Questions

How does plant community diversity influence variation in plant biomass? There are two competing hypotheses: the 'biomass-ratio hypothesis', where biomass is influenced by the abundance and traits of the most dominant species, and the 'diversity hypothesis', where the diversity of organisms influences biomass through mechanisms such as niche complementarity. However, no studies have tested which one of these two hypotheses better explains the variation in plant biomass in the forest understorey.
\end{abstract}

Location

Temperate deciduous forests in Northern France.

Methods

For the forest understorey, we assessed species diversity and biomass as well as soil and light conditions in 133 forest plots of $100 \mathrm{~m}^{2}$ each. Using mixed-effect models and after controlling for potential confounding factors, we tested the 'biomass-ratio hypothesis' by relating the relative 
abundance of the most dominant species across our study sites and the community-weighted mean values (CWM) of plant traits (leaf area and plant height) to biomass. The 'diversity hypothesis' was tested by relating biomass to various measures of taxonomic, functional and phylogenetic diversity.

Results

Biomass of the forest understorey was mainly related to the relative abundance and the trait values of the most dominant species, supporting the 'biomass-ratio hypothesis'. In contrast with the 'diversity hypothesis', functional diversity indices had a negative impact on biomass. We found no contribution of taxonomic or phylogenetic diversity indices.

\section{Conclusion}

The abundance and traits of the most dominant species matter more than taxonomic, functional or phylogenetic diversity of the forest understorey in explaining its biomass. Thus, there is a need for experiments that aim to fully understand keystone species' responses to ongoing changing biotic and abiotic conditions and to predict their effects on ecosystem functioning and processes. 


\section{INTRODUCTION}

There is growing concern about the consequences of biodiversity loss on ecosystem functioning and services (Loreau et al. 2001; Hooper et al. 2005), with the number of studies steadily growing (Gross et al. 2014; Byrnes et al. 2014; Tilman et al. 2014; Zhu et al. 2016; Duffy et al. 2017). However, most of these studies have dealt with aquatic systems, wetlands

This article is protected by copyright. All rights reserved. 
or grasslands (Díaz \& Cabido 2001; Srivastava et al. 2012). Forest ecosystems have only recently come into focus and most available studies focus on the relationship between overstorey diversity and ecosystem functioning (Vilà et al. 2007; Watson et al. 2015; van der Plas et al. 2016; Liang et al. 2016). Yet, forest ecosystems are structurally complex and the influence of other forest tiers, such as the understorey, remains to be investigated (Axmanová et al. 2012; Axmanová et al. 2013; Zhang et al. 2017). For instance, in temperate forests, the forest understorey encompasses a large proportion of vascular plant diversity and plays an important role in ecosystem functioning such as nutrient cycling, organic matter fluxes and as faunal habitat (Whigham 2004; Gilliam 2007). Therefore, it is highly relevant to relate species richness of this key compartment to its above-ground biomass (Axmanová et al. 2012; Axmanová et al. 2013).

Two mutually non-exclusive hypotheses have been proposed to explain variation in ecosystem properties such as biomass (Mokany et al. 2008). First, the 'biomass-ratio' or 'dominance hypothesis' (Grime 1998) postulates that the effect of individual species on ecosystem properties is related to their relative abundance in the community, and that trait values of the dominant species have a proportionally greater effect. There is some evidence that the 'biomass-ratio hypothesis' is relevant to ecosystem processes such as productivity (Garnier et al. 2004; Chanteloup \& Bonis 2013), the rate of litter decomposition (Garnier et al. 2004) and the nitrification rate (Laughlin 2011), all of which impact on biomass. Second, the 'diversity' or 'complementarity hypothesis' proposes that diverse communities have increased influences on ecosystem properties through mechanisms such as complementary resource use and the sampling effect (Tilman et al. 1997). In forest ecosystems, this hypothesis is supported for the overstorey layer and over a wide range of environmental conditions (Hooper et al. 2005; Vilà et al. 2007; Paquette \& Messier 2011; Vilà et al. 2013; Zhang \& Chen 2015). However, whether the strength and the direction of this relationship 
hold for the understorey herb layer has been rarely explored. A notable exception is the study of Zhang et al. (2017), which found that while positive relationships between species richness and above-ground biomass were observed across all vegetation layers, the strength of the effect in the understorey layers was weaker than that for the over-storey layer.

Variation in biomass is largely influenced by available resources and surrounding environmental conditions (Díaz \& Cabido 2001; Fridley 2002) and is therefore contextdependent. Consequently, recent work has suggested that factors such as soil $\mathrm{pH}$, light availability, habitat heterogeneity or disturbances may confound with the 'biomass-ratio' and the 'diversity' hypotheses (Grace et al. 2007; Ma et al. 2010). For instance, in central European oak forests, biomass in the herb layer has been shown to be mainly determined by light availability and to a lesser extent by soil phosphorus concentrations (Axmanová et al. 2013). Thus, environmental factors have a major role in influencing both the potential pool of species and the biomass of keystone species in the habitat (Gough et al. 1994; Schuster \& Diekmann 2005). Therefore, one question is how much of the variation in above-ground biomass could be explained by herbaceous plant community diversity after controlling for the different confounding factors involving environmental conditions.

Studies that aim to test the 'diversity hypothesis' to explain the variation in aboveground biomass usually focus on taxonomic diversity (e.g. species richness), although other components of biodiversity may be stronger predictors of ecosystem properties (Tilman 1999). For example, functional diversity has increasingly been used (Cadotte et al. 2009; Flynn et al. 2011), using various metrics accounting for functional richness, functional evenness and functional divergence (Mason et al. 2005; Villéger et al. 2008; Laliberté \& Legendre 2010). However, this approach presents some shortcomings, such as, for example, the a priori choice of traits (Petchey \& Gaston 2006; Cadotte et al. 2009; Thompson et al. 2015). In contrast, phylogenetic diversity (i.e. a measure of the evolutionary relatedness of 
species in communities; Srivastava et al. 2012) can capture the functional difference between species due to unmeasured traits (Flynn et al. 2011; Srivastava et al. 2012; Thompson et al. 2015). Phylogenetic diversity indices rely on the assumption that phylogenetically related species are likely to share similar functional traits (Losos 2008; Wiens et al. 2010; but see Cavender-Bares et al. 2009; Narwani et al. 2015). Moreover, phylogenetic diversity has been shown to be a good predictor of ecosystem productivity (Cadotte et al. 2009; Flynn et al. 2011; Thompson et al. 2015). To our knowledge, no study has investigated the efficacy of multiple components of biodiversity to explain the variation in above-ground plant biomass in the forest understorey.

In this study, we aim to test which one of the 'biomass-ratio' or the 'diversity' hypotheses best explains plant biomass in the forest understorey, after controlling for the potential confounding effects of light availability and soil factors (e.g. soil pH, phosphorus, moisture and $\mathrm{C}: \mathrm{N}$ ratio).

\section{MATERIALS AND METHODS}

\section{Study design}

We selected nine $5 \mathrm{~km}$ by $5 \mathrm{~km}$ landscape windows representative of temperate lowlands deciduous forests and land uses in Northern France (Hauts-de-France, N49 $25^{\prime}-50^{\circ} 11^{\prime}$; E1 ${ }^{\circ} 52^{\prime}-3^{\circ} 55^{\prime}$; alt. 60-220 m; Fig. 1). In each window, only forest sites capable of containing a $100 \mathrm{~m}^{2}$ quadrat distant from at least $10 \mathrm{~m}$ from the closest edge were retained. We then randomly selected 15 sites per window, giving 135 . The climate in the studied area is oceanic with mean annual temperature and total annual rainfall of $10^{\circ} \mathrm{C}$ and $700 \mathrm{~mm}$, respectively.

\section{Field sampling}

Within each of the 135 sites, we randomly set a $100 \mathrm{~m}^{2}$ plot, and measured the following:

(1) The cover of all vascular plant species present was scored, separately for the tree (>12 m), shrub (1-12 m) and understorey ( $<1 \mathrm{~m})$ layers, using a numeric scale: $0.1,0.5,3,7.5,17.5$, 
37.5, 62.5, and $87.5 \%$. Between 2007 and 2008, all 100m² plots were visited twice, in spring (April-May, collecting only vernal species) and in summer (June-September, collecting remaining species) to cover the entire growing season here in Northern France. Aggregate taxa (e.g. Taraxacum officinale agg. or Rubus fruticosus agg.) were treated as single species.

(2) The biomass of the forest understorey was harvested in three $1 \mathrm{~m}^{2}$ quadrats that were placed at $0,2.25$ and $7.10 \mathrm{~m}$ along a random diagonal of the $100 \mathrm{~m}^{2}$ plot (Fig. 1c). All herbs and lianas creeping on the ground as well as saplings $<1 \mathrm{~m}$ high were harvested, and ovendried (at $60-65^{\circ} \mathrm{C}$ for 72 hours), and weighed. We summed the two harvest values (i.e. spring and summer) to report the average above-ground biomass of the forest understorey in each plot.

\section{Plant functional traits}

For the 162 plant species that we recorded, we compiled values for (i) lateral spread (LS, ordinal scale), (ii) plant height $(\mathrm{H} ; \mathrm{m})$, and (iii) specific leaf area $\left(\mathrm{SLA} ; \mathrm{mm}^{2} \cdot \mathrm{mg}^{-1}\right.$ ) from existing databases (Lambinon et al. 2004; Grime et al. 2007; Kleyer et al. 2008; Landolt et al. 2010). Annual lateral spread is scaled from 1 for therophytes (limited lateral spread) to 5 for perennials (radial spread per year $>1 \mathrm{~m}$ ).

\section{Environmental co-variables factors}

To account for the effect of potentially confounding factors, we measured and collected five sets of abiotic variables.

(1) Soil chemical properties were measured for organic matter content, total nitrogen $(N)$, available phosphorus (Olsen $P$ ) and $p H_{\text {water }}$ following AFNOR French norms (X31-109, X31111, X31-113 and X31-104, respectively). For this, three soil samples from the $0-10 \mathrm{~cm}$ horizon, after litter removal, were collected along the diagonal of the $100 \mathrm{~m}^{2}$ plot. 
(2) Light availability to the forest understorey was measured using two indices: the percentage cover of the canopy, and the shade casting ability of the canopy species (Verheyen et al. 2012). The percentage cover of each layer (trees: >12 m, shrubs: 1-12 m) was visually estimated in the field. The combined cover of woody layers (trees and shrubs) or total canopy cover hereafter served as a proxy for light reaching the herb layer and was computed following Fischer (2015). Second, the shade casting ability index (SCA) is an expert-based, species-specific index that varies between 1 and 5 (low to high shade casting ability of the canopy tree species; Verheyen et al. 2012). Community weighted mean (CWM) values of the SCA index were calculated for each individual $100 \mathrm{~m}^{2}$ plot based on the index of each individual tree weighted by its cover within the plot.

(3) The surrounding landscape was described as percentage cover of grasslands, forests (deciduous and coniferous) and croplands within a 500m radius around the focal plot.

(4) The distance to the closest edge of the forest from the centre of the $100 \mathrm{~m}^{2}$ plot was calculated.

(5) Ellenberg indicator values (EIV) were used to estimate local environmental conditions for light $(L)$, soil nutrients $(N)$, soil $\mathrm{pH}(R)$ and soil moisture $(F)$ (Ellenberg et al. 1999). Ellenberg et al. (1999) ranked most of the central European vascular plant species according to the position of their realised optimum along the above-mentioned ecological gradients. For each of these environmental variables, unweighted EIVs of all species co-occurring in each plot were averaged.

\section{Explanatory variables}

To explain biomass of the forest understorey (the response variable), we used four groups of variables capturing the 'biomass-ratio' and 'diversity' hypotheses (see below) together with the potential confounding factors due to local environmental conditions (see the 'Statistical analyses' section for the selection of the covariates) as explanatory variables. 
(1) Dominance: To investigate the relative importance of "abundant" species on total biomass, we used two approaches. First, a CWM of trait values was calculated for each quantitative trait (i.e. SLA and height) (Díaz et al. 2007; Lavorel et al. 2008). CWM is a direct extension of the 'biomass-ratio hypothesis' (Grime 1998) and represents functional dominance (sometimes called functional identity) (Mokany et al. 2008). Second, for the two most dominant species across our whole study area, namely Ivy (Hedera helix L.) and Blackberry (Rubus fruticosus L.), we calculated their covers relative to the total cover of all species in each plot. Ivy and Blackberry were selected as the collected biomass was always high when Ivy and/or Blackberry was present in the plot and because of their high cover values in the dataset (Fig. 2).

(2) Taxonomic diversity (TD): Four indices were computed: species richness (i.e. number of species per plot; $S R)$; Shannon's diversity $\left(H^{\prime}\right)$; Simpson's diversity $(D)$; and Pielou's equitability $\left(J^{\prime}=H^{\prime} / \ln (S R)\right)$.

(3) Functional diversity (FD): We used three traits: lateral spread (LS), plant height (H); and specific leaf area (SLA) (Appendix S1). We first computed a principal coordinate analysis (PCoA) on the matrix of species-by-species Gower distances, corrected using Cailliez's method (Cailliez 1983) to avoid negative eigenvalues. The resulting axes were used to build the multidimensional trait space within which three complementary FD indices were computed: functional richness (FRic), functional evenness (FEve), and functional divergence (FDiv) (Villéger et al. 2008; Mouchet et al. 2010; Laliberté \& Legendre 2010). FRic measures the $n$-dimensional functional hypervolume enclosing all species co-occurring in the community. A low FRic value means that part of the studied trait space is unused (Mason et al. 2005). By contrast, FEve measures evenness in abundance distributions in the $n$ dimensional trait space (a convex hull). Values close to 0 mean that some species are tightly packed in only some parts of the $n$-dimensional trait space. FDiv quantifies how species 
diverge, in terms of Euclidean distances (weighted by their abundance), from the centre of gravity of the $n$-dimensional trait space. FDiv also ranges from 0 to 1 : values close to 1 mean a high degree of functional niche differentiation among species (Mouchet et al. 2010), whilst values approach 0 when highly abundant species are very close to the centre of gravity relative to rare species (Villéger et al. 2008). Further, we computed Rao's $Q$ quadratic entropy (Botta-Dukát 2005; Laliberté \& Legendre 2010), which estimates how species are dispersed in the $n$-dimensional trait space (Laliberté \& Legendre 2010). FEve and Rao's $Q$ are unaffected by species richness and outliers, and have no loss of information associated with reduced space ordination and subsequent calculations (Villéger et al. 2008; Laliberté \& Legendre 2010). Note that when computing FRic and FDiv, the number of species cooccurring within the focal community must always exceed the number of PCoA axes retained to build the $n$-dimensional trait space. For that reason, only 133 (out of 135) plots could be used for computation of FRic, any bias being insignificant. Calculations of all functional diversity indices used the package 'FD' (Laliberté et al. 2014) implemented in R version 3.4.1.

(4) Phylogenetic diversity (PD): We first extracted a phylogenetic tree for the 162 vascular plant species occurring in our study from a dated, ultrametric super tree containing 4685 Central European vascular plant species (Durka \& Michalski 2012). The final tree included 155 tips and 150 internal nodes (Appendix S1). We computed four complementary metrics. First, we computed the Faith's $P D$ index, which is the minimum tree length containing all the taxa to the root of the tree (Faith 1992). Then, we computed phylogenetic species' variability (PSV; Helmus et al. 2007), which measures the variance among species of a community in the value of a hypothetical neutral trait evolving under a Brownian motion model; a higher phylogenetic relatedness produces lower values of $P S V$ than expected by chance. Third, we computed phylogenetic species richness (PSR; Helmus et al. 2007) which 
is $P S V$ multiplied by the number of species in the focal community and indicates species richness of a community after discounting species relatedness; it decreases towards zero as relatedness among species increases. Finally, we computed the phylogenetic species evenness (PSE; Helmus et al. 2007) which is a modification of PSV that incorporates relative species covers; the maximum value of 1 is reached only if species' abundances are equal and the species' phylogeny is a star, i.e. the community has no phylogenetic structure. All $P D$ indices were calculated using the package 'pez' (Pearse et al. 2014) in R version 3.4.1.

\section{Statistical analyses}

We first assessed Pearson's correlations among the 13 variables used to describe local environmental conditions in order to avoid multi-collinearity issues in our models (Appendix S2). Mean Ellenberg values for $\mathrm{R}(m e a n R)$ were highly correlated with soil $p H$. Percentage cover of forest (Prop-forest) and percentage cover of croplands (Prop-croplands) within a $500 \mathrm{~m}$ radius around the focal plot were highly negatively correlated. In addition, Prop-forest was also correlated with meanR and the distance to the closest forest edge (Edge-distance) variables (Appendix S2). Except for Prop-forest and meanR, the above-mentioned variables were all used as covariates. Fitting a more parsimonious model (i.e. a model with a minimal set of predictor variables) throughout a stepwise regression technique did not give different results/conclusions than fitting the full model. For that reason, we decided to report only the results from the full models in order to take into account all the potential determinants of biomass in the forest understorey. We first analysed the respective effects of the 11 selected environmental covariates on biomass (hereafter, the baseline model).

We fitted 16 'mono-faceted' candidate models (i.e. one per dominance/diversity index) and used Akaike's Information Criterion (AIC) value to compare model performances, preferring the models with the lowest AIC (Burnham \& Anderson 2003). Furthermore, based on the best mono-faceted models and multi-collinearity issues (see Appendix S3 for 
Pearson's correlation values among the 16 dominance/diversity variables explored in this study), we then fitted one 'multi-faceted' model, including all dominance/diversity indices at once, to test potential confounding effects between the studied dominance/diversity indices.

The response variable (biomass) was Box-Cox transformed (Box \& Cox 1964) to improve normality and all the continuous explanatory variables were standardized, i.e., the value for each variable was subtracted from its mean and divided by its standard deviation (Schielzeth 2010). To account for the sampling structure of our study design, we used linear mixed-effect models (LMMs) with the windows variable (a factor variable with 9 levels) as a random intercept term in all our LMMs. Statistical analyses were performed using the packages 'Ime4', 'forcast', 'moments', 'multcomp' and 'MuMIn' in the software R version 3.4.1.

\section{RESULTS}

Mean values for each soil variable were used as a proxy for resource availability. Soil $p H$ ranges from 3 to 7.8 (mean \pm SD: $4.9 \pm 1.4$ ) and available $P$ ranges between 2.15 to 74.6 $($ mean $\pm \mathrm{SD}: 12.4 \pm 8.7) \mathrm{mg}$ Olsen-P.kg${ }^{-1}$ across the 135 studied plots. Biomass in the understorey ranged from 7.3 to $464.4 \mathrm{~g} \mathrm{~m}^{-2}$ (mean $\pm \mathrm{SD}$ : $130 \pm 102.5$ ) across the study area. The results of the baseline model (i.e. the model that tests the relative contribution of the 11 environmental covariates on biomass) showed that both Prop-croplands (i.e. percentage of croplands within a 500m radius) and soil $p H$ had positive relationships ( $p$-value $<0.05$; Table 1, Fig. 3a, b) with biomass.

Results from the 16 mono-faceted models (Table 2) showed that the effect of the relative abundance of Ivy on biomass was positive and its effect size the highest $(p$-value $<<$ 0.05; Table 2d). The community-weighted mean trait values for SLA $\left(C W M_{S L A}\right)$ were found to negatively relate to biomass ( $p$-value $=0.01$; Table $2 \mathrm{~d}$ ). Among $F D$ indices $($ Table $2 \mathrm{~b}$ ), only Rao's $Q$ index had a negative relationship with biomass. Neither taxonomic nor

This article is protected by copyright. All rights reserved. 
phylogenetic indices showed any significant effect (Table 2a, c). Among the environmental covariates, Prop-croplands had a positive relationship with biomass in all mono-faceted models, except for the model including $I v y$. Soil $p H$ also had a positive relationship with biomass in all mono-faceted models except the ones including Ivy and FDiv. Interestingly, in the mono-faceted model that includes Ivy with all the environmental covariates, only meanF (mean Ellenberg value for moisture) had a positive relationship with biomass ( $p$-value $=$ 0.047) (Fig. 3c).

The multi-faceted model includes Pielou J, Rao's $Q, P S E$, Ivy and $C W M_{S L A}$ indices (Table 3). Only Ivy (i.e. its relative abundance) had a positive relationship with biomass ( $p$ value $=0.001$; Fig. 3d), while none of the investigated diversity indices did (Table 3a-c). Among the environmental covariates, only mean $F$ had a positive relationship with biomass (Table 3e; Fig. 3c).

\section{DISCUSSION}

Our objective was to test which of the 'biomass-ratio' or the 'diversity' hypotheses is more important in explaining biomass in the forest understorey of temperate deciduous forests. Our results showed that the 'biomass-ratio hypothesis' explains more variation in biomass in the forest understorey than the 'diversity hypothesis'. Contrary to what was expected under the 'diversity hypothesis', when significant, we found a negative relationship between functional diversity and above-ground biomass in the forest understorey, suggesting higher biomass in functionally-poor understorey plant communities, which further advocates in favour of the 'biomass-ratio hypothesis'. Furthermore, we did not find evidence for taxonomic nor phylogenetic diversity in explaining above-ground biomass in the forest understorey, suggesting that species richness per se may not be a good predictor of biomass.

This article is protected by copyright. All rights reserved. 
The relative abundance of the most dominant species (Hedera helix), as well as community weighted mean trait values (CWM) for specific leaf area (SLA), were highly related to biomass supports the 'biomass-ratio hypothesis'. While a close relationship between the CWM trait values for SLA and above-ground biomass production is expected under the 'biomass-ratio hypothesis', there is no consensus in the literature about the slope of this relationship. In our study, we found a negative relationship between biomass and CWM for SLA, which contradicts the results of other studies (e.g. Chanteloup \& Bonis 2013). Our result could be explained by the fact that plants with thicker leaves (hence low SLA) may have higher photosynthetic rates and, consequently, higher biomass production (Thumma et al. 2001; Marron et al. 2005). Interestingly, while our most abundant species (Hedera helix) was the best predictor of biomass in our study, our second most abundant species (Rubus fructicosus) did not show any significant effect. This result highlights the importance of Hedera helix as a keystone species in the forest system and may suggest that different species could have unique contributions to ecosystem functioning and processes (Naeem 1998). That may further raise the importance of considering the consequence of the loss/gain of a keystone species on ecosystem functioning under the context of climate change. For instance, Hedera helix increases in abundance in temperate Europe as a result of mild winters (Heinrichs \& Schmidt 2014), with important consequences for biomass and carbon sequestration in the forest understorey.

None of taxonomic, functional or phylogenetic diversity explains the biomass in the forest understorey of temperate deciduous forests. In contrast to many previous studies (e.g. Loreau et al. 2001; Hooper et al. 2005), our study showed that taxonomic diversity was not related to biomass of the forest understorey, perhaps because we are missing communities with very low species richness (Hooper et al. 2005; Chanteloup \& Bonis 2013). For instance, 
it has been shown that a significant effect of species richness on biomass production disappeared when species richness increased beyond a minimum (generally around four or five) (Hooper et al. 2005; Chanteloup \& Bonis 2013). In our communities, the minimum species richness was four species, lacking very low values for species richness.

Among the functional diversity indices, only $R a o$ 's $Q$ index had a significant, but negative, relationship with biomass. Although surprising at first glance, this may be explained by the dominance of highly competitive and productive species within communities with a low level of FD (Mokany et al. 2008; Chanteloup \& Bonis 2013). This is consistent with Mokany et al. (2008), who demonstrated that root biomass in temperate native grasslands was negatively related to $F D$, and that high root biomass was likely achieved by a less diverse community with most species present possessing large roots. This pleads for the 'biomass-ratio hypothesis': the relative abundance of the most dominant species is more important than FD per se. However, while Rao's $Q$ index was significant in the mono-faceted model, its effect disappeared in the multi-faceted model, suggesting a confounding effect with the other dominance/diversity variables.

We did not find any effect of phylogenetic diversity on biomass production either, irrespective of the model type (mono- or multi-faceted). Although it has been acknowledged that $P D$ indices should complement $F D$ indices to capture unmeasured components of $F D$ (Flynn et al. 2011), recent attention has been given to the pitfalls of integrating phylogenetics into studies of community assembly (Gerhold et al. 2015; Kraft et al. 2015) and ecosystem functioning (Narwani et al. 2015; Venail et al. 2015). For example, PD has no influence on ecosystem functioning whenever the functional variation among species is not explained by their phylogenetic relatedness (Venail et al. 2015). Despite our expectation of low $P D$ 
variability among our plots (due to a relatively small studied area with the same regional species pool), we tested PD. $P D$ failed to predict above-ground biomass and thus, we were proved correct.

Abiotic factors typically explain a significant amount of the variation in ecosystem properties such as biomass (Loreau et al. 2001; Axmanová et al. 2012) and an increasing number of studies have demonstrated that changes in environmental conditions could alter the shape of the relationship between biodiversity and ecosystem functioning (Steudel et al. 2012; Isbell et al. 2013). In this context, soil phosphorus availability and moisture have been shown to be important factors influencing the forest understorey biomass in temperate forests (Axmanová et al. 2011). However, we did not find any effect of phosphorus availability on biomass in our study. Interestingly, while $\mathrm{pH}$ and Prop-croplands (percentage of croplands within a 500m radius) had significant effects in the baseline model (i.e. the model that tests the relative contribution of the environmental covariates on biomass), they were no longer significant in the mono-faceted model that includes Ivy (as an abundance score). In addition, in that model only soil moisture (as mean Ellenberg values) showed a significant positive relationship with biomass. This could mean that the abundance of Ivy is significantly related to these environmental variables. In order to test this hypothesis, we ran an additional linear mixed-effects model where the relationship of environmental variables to the relative abundance of Ivy was tested (Appendix S4), and it was only significantly related to soil $p H$. Taken together, this suggests that Hedera helix appears a good bio-indicator of soil $\mathrm{pH}$ here and that it may act as a biotic mediator of changes in these abiotic conditions.

In general, none of the dominance/diversity metrics investigated in this study were sufficient to explain the observed variation in biomass of the understorey plant communities in Northern France. This suggests that we are either missing important environmental variables that are highly variable across the study area or that other components of 
biodiversity that we did not investigate yet may matter. Intraspecific genetic diversity is a potential candidate that we did not investigate here. For instance, it has already been demonstrated that it can shape net primary productivity and ecosystem functioning (Crutsinger et al. 2006; Breza et al. 2012). We argue that there is no single measure that can capture all components of biodiversity, but that all together are important to complete the puzzle. Further investigations accounting for all these components of biodiversity (both interspecific and intraspecific) and focusing on temperate deciduous forest ecosystems where the understorey plant communities play an important role in ecosystem functioning should be carried out to disentangle the drivers of plant biomass.

\section{ACKNOWLEDGMENTS}

We greatly acknowledge the Syrian Ministry of Higher Education for funding SW's PhD thesis. We are grateful to the many people who collected biomass data, especially Déborah Closset-Kopp, Olivia Semboli, Clément Chenot and Olivier Chabrerie. We thank Marta A. Jarzyna for insightful comments on a former version of our manuscript. We also wish to thank two anonymous referees and Gillian Rapson for insightful comments as well as Emilie Gallet-Moron for help in preparing geographical maps. RB's work was supported by the TULIP Laboratory of Excellence (ANR-10-LABX-41). KV was supported by the European Research Council (ERC Consolidator grant no. 614839: PASTFORWARD).

\section{AUTHOR CONTRIBUTIONS}

SW, JL and GD conceived and designed the experiments as well as the analytical framework. SW, JL, AJ, RS, LB, AV and GD collected the data. TH prepared the phylogeny as well as provided help to compute the functional and phylogenetic diversity metrics. EGM provided maps and GIS support. SW analysed the data with the support of JL and wrote the manuscript with JL, KV and GD. All authors provided feedbacks on the initial version of the manuscript. 


\section{REFERENCES}

Axmanová, I., Chytrý, M., Danihelka, J., Lustyk, P., Kočí, M., Kubešová, S., Horsák, M., Cherosov, M.M., \& Gogoleva, P.A. 2013. Plant species richness-productivity relationships in a low-productive boreal region. Plant Ecology 214: 207-219.

Axmanová, I., Chytrý, M., Zelený, D., Li, C.-F., Vymazalová, M., Danihelka, J., Horsák, M., Kočí, M., Kubesova, S., Lososová, Z., Otýpková, Z., Tichý, L., Martynenko, V.B., Baisheva, E.Z., Schuster, B., \& Diekmann, M. 2012. The species richnessproductivity relationship in the herb layer of European deciduous forests. Global Ecology and Biogeography 21: 657-667.

Axmanová, I., Zelený, D., Li, C-F., \& Chytrý, M. 2011. Environmental factors influencing herb layer productivity in Central European oak forests: insights from soil and biomass analyses and a phytometer experiment. Plant and Soil 342: 183-194.

Botta-Dukát, Z. 2005. Rao's quadratic entropy as a measure of functional diversity based on multiple traits. Journal of Vegetation Science 16: 533-540.

Box, G.E.P., \& Cox, D.R. 1964. An analysis of transformations. Journal of the Royal Statistical Society. Series B (Methodological), 26: 211-252.

Breza, L.C., Souza, L., Sanders, N.J., \& Classen, A.T. 2012. Within and between population variation in plant traits predicts ecosystem functions associated with a dominant plant species. Ecology and Evolution 2: 1151-1161.

Burnham, K.P., \& Anderson, D.R. 2003. Model Selection and Multimodel Inference: A Practical Information-Theoretic Approach. Springer Science \& Business Media.

Byrnes, J.E.K., Gamfeldt, L., Isbell, F., Lefcheck, J.S., Griffin, J.N., Hector, A., Cardinale, B.J., Hooper, D.U., Dee, L.E., \& Emmett Duffy, J. 2014. Investigating the relationship between biodiversity and ecosystem multifunctionality: challenges and solutions. Methods in Ecology and Evolution 5: 111-124.

Cadotte, M.W., Cavender-Bares, J., Tilman, D., \& Oakley, T.H. 2009. Using phylogenetic, functional and trait diversity to understand patterns of plant community productivity. PloS One 4: e5695.

Cailliez, F. 1983. The analytical solution of the additive constant problem. Psychometrika 48: 305-308.

Cavender-Bares, J., Kozak, K.H., Fine, P.V.A., \& Kembel, S.W. 2009. The merging of community ecology and phylogenetic biology. Ecology Letters 12: 693-715.

Chanteloup, P., \& Bonis, A. 2013. Functional diversity in root and above-ground traits in a fertile grassland shows a detrimental effect on productivity. Basic and Applied Ecology 14: 208-216.

Crutsinger, G.M., Collins, M.D., Fordyce, J.A., Gompert, Z., Nice, C.C., \& Sanders, N.J. 2006. Plant genotypic diversity predicts community structure and governs an ecosystem process. Science 313: 966-968. 
Díaz, S., \& Cabido, M. 2001. Vive la difference: plant functional diversity matters to ecosystem processes. Trends in Ecology \& Evolution 16: 646-655.

Díaz, S., Lavorel, S., de Bello, F., Quétier, F., Grigulis, K., \& Robson, T.M. 2007. Incorporating plant functional diversity effects in ecosystem service assessments. Proceedings of the National Academy of Sciences of the United States of America 104: 20684-9.

Duffy, J.E., Godwin, C.M., \& Cardinale, B.J. 2017. Biodiversity effects in the wild are common and as strong as key drivers of productivity. Nature 549: 261-264.

Durka, W., \& Michalski, S.G. 2012. Daphne: a dated phylogeny of a large European flora for phylogenetically informed ecological analyses: Ecological Archives E093-214. Ecology 93: 2297-2297.

Ellenberg, H., Weber, H., Düll, R., Wirth, V., Werner, W., \& Pauliben, D. 1999. Zeigerwerte von Pflanzen in Mitteleuropa. Scripta Geobotanica 18: 1-248.

Faith, D.P. 1992. Conservation evaluation and phylogenetic diversity. Biological Conservation 61: 1-10.

Fischer, H.S. 2015. On the combination of species cover values from different vegetation layers. Applied Vegetation Science 18: 169-170.

Flynn, D.F.B., Mirotchnick, N., Jain, M., Palmer, M.I., \& Naeem, S. 2011. Functional and phylogenetic diversity as predictors of biodiversity-ecosystem-function relationships. Ecology 92: 1573-1581.

Fridley, J.D. 2002. Resource availability dominates and alters the relationship between species diversity and ecosystem productivity in experimental plant communities. Oecologia 132: 271-277.

Garnier, E., Cortez, J., Billès, G., Navas, M.-L., Roumet, C., Debussche, M., Laurent, G., Blanchard, A., Aubry, D., Bellmann, A., Neill, C., \& Toussaint, J.-P. 2004. Plant functional markers capture ecosystem properties during secondary succession. Ecology 85: 2630-2637.

Gerhold, P., Cahill, J.F., Winter, M., Bartish, I.V., \& Prinzing, A. 2015. Phylogenetic patterns are not proxies of community assembly mechanisms (they are far better). Functional Ecology 29: 600-614.

Gilliam, F.S. 2007. The ecological significance of the herbaceous layer in temperate forest ecosystems. Bioscience 57: 845-858.

Gough, L., Grace, J.B., \& Taylor, K.L. 1994. The relationship between species richness and community biomass: the importance of environmental variables. Oikos 70: 271-279.

Grace, J.B., Anderson, T.M., Smith, M.D., Seabloom, E., Andelman, S.J., Meche, G., Weiher, E., Allain, L.K., Jutila, H., Sankaran, M., Knops, J., Ritchie, M., \& Willig, M.R. 2007. Does species diversity limit productivity in natural grassland communities? Ecology Letters 10: 680-689.

This article is protected by copyright. All rights reserved. 
Grime, J.P. 1998. Benefits of plant diversity to ecosystems: immediate, filter and founder effects. Journal of Ecology 86: 902-910.

Grime, J.P., Hodgson, J.G., \& Hunt, R. 2007. Comparative Plant Ecology: A Functional Approach to Common British Species., 2nd edition. Springer.

Gross, K., Cardinale, B.J., Fox, J.W., Gonzalez, A., Loreau, M., Polley, H.W., Reich, P.B., \& van Ruijven, J. 2014. Species richness and the temporal stability of biomass production: a new analysis of recent biodiversity experiments. American Naturalist 183: $1-12$.

Heinrichs, S., \& Schmidt, W. 2014. Dynamics of Hedera helix L. in Central European beech forests on limestone: results from long-term monitoring and experimental studies. Plant Ecology 216: 1-15.

Helmus, M.R., Bland, T.J., Williams, C.K., \& Ives, A.R. 2007. Phylogenetic measures of biodiversity. The American Naturalist 169: E68-E83.

Hooper, D.U., Chapin, F.S., Ewel, J.J., Hector, A., Inchausti, P., Lavorel, S., Lawton, J.H., Lodge, D.M., Loreau, M., Naeem, S., Schmid, B., Setala, H., Symstad, A.J., Vandermeer, J., \& Wardle, D.A. 2005. Effects of biodiversity on ecosystem functioning: A consensus of current knowledge. Ecological Monographs 75: 3-35.

Isbell, F., Reich, P.B., Tilman, D., Hobbie, S.E., Polasky, S., \& Binder, S. 2013. Nutrient enrichment, biodiversity loss, and consequent declines in ecosystem productivity. Proceedings of the National Academy of Sciences 110: 11911-11916.

Kleyer, M., Bekker, R.M., Knevel, I.C., Bakker, J.P., Thompson, K., Sonnenschein, M., Poschlod, P., Groenendael, V., M, J., Klimes, L., (...) \& Peco, B. 2008. The LEDA Traitbase: a database of life-history traits of the Northwest European flora. Journal of Ecology 96: 1266-1274.

Kraft, N.J.B., Adler, P.B., Godoy, O., James, E.C., Fuller, S., \& Levine, J.M. 2015. Community assembly, coexistence and the environmental filtering metaphor. Functional Ecology 29: 592-599.

Laliberté, E., \& Legendre, P. 2010. A distance-based framework for measuring functional diversity from multiple traits. Ecology 91: 299-305.

Laliberté, E., Legendre, P., \& Shipley, B. 2014. FD: Measuring functional diversity from multiple traits, and other tools for functional ecology. R package version 1: 0-12.

Lambinon, J., De Langhe, J.E., Delvosalle, L., \& Duvigneaud, J. 2004. Nouvelle flore de la Belgique, du Grand-Duche de Luxembourg, du Nord de la France et des regions voisines (Pteridophytes et Spermatophytes). Jardin Botanique National de Belgique, Meise, Belgium.

Landolt, E., Bäumler, B., Erhad, A., Hegg, O., Klötzli, F., \& Lämmler, W. 2010. Flora indicativa: ecological indicator values and biological attributes of the flora of Switzerland and the Alps. Haupt Verlag Ag, Bern; Stuttgart; Wien.

Laughlin, D.C. 2011. Nitrification is linked to dominant leaf traits rather than functional

This article is protected by copyright. All rights reserved. 
diversity. Journal of Ecology 99: 1091-1099.

Lavorel, S., Grigulis, K., McIntyre, S., Williams, N.S.G., Garden, D., Dorrough, J., Berman, S., Quétier, F., Thébault, A., \& Bonis, A. 2008. Assessing functional diversity in the field - methodology matters! Functional Ecology 22: 134-147.

Liang, J., Crowther, T.W., Picard, N., Wiser, S., Zhou, M., Alberti, G., Schulze, E.-D., McGuire, A.D., Bozzato, F., (...) \& Reich, P.B. 2016. Positive biodiversityproductivity relationship predominant in global forests. Science 354(6309).

Loreau, M., Naeem, S., Inchausti, P., Bengtsson, J., Grime, J.P., Hector, A., Hooper, D.U., Huston, M.A., Raffaelli, D., Schmid, B., Tilman, D., \& Wardle, D.A. 2001. Biodiversity and ecosystem functioning: current knowledge and future challenges. Science 294: 804-808.

Losos, J.B. 2008. Phylogenetic niche conservatism, phylogenetic signal and the relationship between phylogenetic relatedness and ecological similarity among species. Ecology Letters 11: 995-1003.

Ma, W., He, J.-S., Yang, Y., Wang, X., Liang, C., Anwar, M., Zeng, H., Fang, J., \& Schmid, B. 2010. Environmental factors covary with plant diversity-productivity relationships among Chinese grassland sites. Global Ecology and Biogeography 19: 233-243.

Marron, N., Villar, M., Dreyer, E., Delay, D., Boudouresque, E., Petit, J.-M., Delmotte, F.M., Guehl, J.-M., \& Brignolas, F. 2005. Diversity of leaf traits related to productivity in 31 Populus deltoides x Populus nigra clones. Tree Physiology 25: 425-435.

Mason, N.W.H., Mouillot, D., Lee, W.G., \& Wilson, J.B. 2005. Functional richness, functional evenness and functional divergence: the primary components of functional diversity. Oikos 111: 112-118.

Mokany, K., Ash, J., \& Roxburgh, S. 2008. Functional identity is more important than diversity in influencing ecosystem processes in a temperate native grassland. Journal of Ecology 96: 884-893.

Mouchet, M.A., Villéger, S., Mason, N.W.H., \& Mouillot, D. 2010. Functional diversity measures: An overview of their redundancy and their ability to discriminate community assembly rules. Functional Ecology 24: 867-876.

Naeem, S. 1998. Species redundancy and ecosystem reliability. Conservation Biology 12: $39-45$.

Narwani, A., Matthews, B., Fox, J., \& Venail, P. 2015. Using phylogenetics in community assembly and ecosystem functioning research. Functional Ecology 29: 589-591.

Paquette, A., \& Messier, C. 2011. The effect of biodiversity on tree productivity: from temperate to boreal forests. Global Ecology and Biogeography 20: 170-180.

Pearse, W.D., Purvis, A., Cavender-Bares, J., \& Helmus, M.R. 2014. Metrics and models of community phylogenetics. In Modern phylogenetic comparative methods and their application in Evolutionary Biology, pp. 451-464. Springer, Berlin, Heidelberg.

This article is protected by copyright. All rights reserved. 
Petchey, O.L., \& Gaston, K.J. 2006. Functional diversity: back to basics and looking forward. Ecology Letters 9: 741-758.

van der Plas, F., Manning, P., Allan, E., Scherer-Lorenzen, M., Verheyen, K., Wirth, C., Zavala, M.A., Hector, A., Ampoorter, E., (...) \& Fischer, M. 2016. Jack-of-all-trades effects drive biodiversity-ecosystem multifunctionality relationships in European forests. Nature Communications 7: 11109.

Schielzeth, H. 2010. Simple means to improve the interpretability of regression coefficients. Methods in Ecology and Evolution 1: 103-113.

Schuster, B., \& Diekmann, M. 2005. Species richness and environmental correlates in deciduous forests of Northwest Germany. Forest Ecology and Management 206: 197205.

Srivastava, D.S., Cadotte, M.W., MacDonald, A.A.M., Marushia, R.G., \& Mirotchnick, N. 2012. Phylogenetic diversity and the functioning of ecosystems. Ecology Letters 15: 637-648.

Steudel, B., Hector, A., Friedl, T., Löfke, C., Lorenz, M., Wesche, M., \& Kessler, M. 2012. Biodiversity effects on ecosystem functioning change along environmental stress gradients. Ecology Letters 15: 1397-1405.

Thompson, P.L., Davies, T.J., \& Gonzalez, A. 2015. Ecosystem functions across trophic levels are linked to functional and phylogenetic diversitylalibérté. Plos One 10: e0117595.

Thumma, B.R., Naidu, B.P., Chandra, A., Cameron, D.F., Bahnisch, L.M., \& Liu, C. 2001. Identification of causal relationships among traits related to drought resistance in Stylosanthes scabra using QTL analysis. Journal of Experimental Botany 52: 203214.

Tilman, D. 1999. Diversity and production in European grassland. Science 286: 1099-1100.

Tilman, D., Isbell, F., \& Cowles, J.M. 2014. Biodiversity and Ecosystem Functioning. Annual Review of Ecology, Evolution, and Systematics 45: 471-493.

Tilman, D., Lehman, C.L., \& Thomson, K.T. 1997. Plant diversity and ecosystem productivity: Theoretical considerations. Proceedings of the National Academy of Sciences 94: 1857-1861.

Venail, P., Gross, K., Oakley, T.H., Narwani, A., Allan, E., Flombaum, P., Isbell, F., Joshi, J., Reich, P.B., Tilman, D., van Ruijven, J., \& Cardinale, B.J. 2015. Species richness, but not phylogenetic diversity, influences community biomass production and temporal stability in a re-examination of 16 grassland biodiversity studies. Functional Ecology 29: 615-626.

Verheyen, K., Baeten, L., De Frenne, P., Bernhardt-Römermann, M., Brunet, J., Cornelis, J., Decocq, G., Dierschke, H., Eriksson, O., (...) \& Verstraeten, G. 2012. Driving factors behind the eutrophication signal in understorey plant communities of deciduous temperate forests. Journal of Ecology 100: 352-365. 
Vilà, M., Carrillo-Gavilan, A., Vayreda, J., Bugmann, H., Fridman, J., Grodzki, W., Haase, J., Kunstler, G., Schelhaas, M., \& Trasobares, A. 2013. Disentangling biodiversity and climatic determinants of wood production. Plos One 8: e53530.

Vilà, M., Vayreda, J., Comas, L., Ibáñez, J.J., Mata, T., \& Obon, B. 2007. Species richness and wood production: a positive association in Mediterranean forests. Ecology Letters 10: $241-250$.

Villéger, S., Mason, N.W.H., \& Mouillot, D. 2008. New multidimensional functional diversity indices for a multifaceted framwork in functional ecology. Ecology 89: 2290-2301.

Watson, J.V., Liang, J., Tobin, P.C., Lei, X., Rentch, J.S., \& Artis, C.E. 2015. Large-scale forest inventories of the United States and China reveal positive effects of biodiversity on productivity. Forest Ecosystems 2: 22.

Whigham, D.F. 2004. Ecology of woodland herbs in temperate deciduous forests. Annual Review of Ecology, Evolution, and Systematics 35: 583-621.

Wiens, J.J., Ackerly, D.D., Allen, A.P., Anacker, B.L., Buckley, L.B., Cornell, H.V., Damschen, E.I., Jonathan Davies, T., Grytnes, J.-A., Harrison, S.P., Hawkins, B.A., Holt, R.D., McCain, C.M., \& Stephens, P.R. 2010. Niche conservatism as an emerging principle in ecology and conservation biology. Ecology Letters 13: 13101324.

Zhang, Y., \& Chen, H.Y.H. 2015. Individual size inequality links forest diversity and aboveground biomass. Journal of Ecology 103: 1245-1252.

Zhang, Y., Chen, H.Y.H., \& Taylor, A.R. 2017. Positive species diversity and above-ground biomass relationships are ubiquitous across forest strata despite interference from overstorey trees. Functional Ecology 31: 419-426.

Zhu, J., Jiang, L., Zhang, Y., Loreau, M., Tilman, D., Snell-Rood, E.C., Tilman, D., Levin, S.A., Cadotte, M.W., (...) \& Lu, Q. 2016. Relationships between functional diversity and aboveground biomass production in the Northern Tibetan alpine grasslands. Scientific Reports 6: 34105-34105.

This article is protected by copyright. All rights reserved. 


\section{TABLES}

Table 1. Summary table of the linear mixed-effect model (LMM) testing the relationship between biomass and environmental drivers. Environmental factors are soil $p H$; available soil phosphorus $(P)$; soil carbon-nitrogen ratio; canopy cover; shade casting ability $(S C A)$; mean Ellenberg values for light (meanL), nitrogen $($ mean $N)$ and soil humidity (meanF); percentage cover of grasslands (Prop-grasslands) and croplands (Prop-croplands) within a 500m radius around the focal plot, and the distance to the closest edge of the forest (Edge-distance). The $\mathrm{R}^{2}$ values represent the total variance explained by both fixed and random factors (i.e. the entire model). Parameters with significant relations are depicted in bold.

\begin{tabular}{lll}
\hline Parameter & Estimate & $p$-value \\
\hline (Intercept) & $\mathbf{7 . 6}$ & $<\mathbf{1 0}^{-4}$ \\
Soil pH & $\mathbf{0 . 4 5}$ & $\mathbf{0 . 0 4}$ \\
Available P & -0.023 & 0.9 \\
Carbon:Nitrogen & 0.2 & 0.4 \\
Canopy cover & -0.14 & 0.4 \\
SCA & 0.17 & 0.32 \\
MeanL & 0.20 & 0.31 \\
MeanN & 0.33 & 0.16 \\
MeanF & 0.10 & 0.15 \\
Prop-grasslands & 0.28 & 0.37 \\
Prop-croplands & $\mathbf{0 . 7 6}$ & $\mathbf{0 . 0 0 8}$ \\
Edge-distance & 0.26 & 0.23 \\
\hline AIC & 562.5 & \\
$\mathrm{R}^{\mathbf{2}}$ & 0.28 & \\
\hline
\end{tabular}

This article is protected by copyright. All rights reserved. 
Table 2. Summary table of mono-faceted models for all the linear mixed-effect models (LMMs) testing the relationship between biomass and dominance, taxonomic, functional, and phylogenetic diversities. Note that all LMMs also include environmental confounding variables (see Table 1 for the list of environmental variables) as fixed effects. The $\mathrm{R}^{2}$ values represent the total variance explained by the entire model. The rows of dominance/diversity indices having a significant relationship to biomass (i.e., p-value <0.05) are in bold. Parameters for confounding environmental factors are not shown.

\begin{tabular}{lllccc}
\hline Indices & Parameter & Estimate & $\mathrm{p}$-value & $\mathrm{R}^{2}$ & $\mathrm{AIC}$ \\
\hline Taxonomic & Species richness & 0.049 & 0.8 & 0.28 & 564.43 \\
& Shannon H & -0.204 & 0.26 & 0.28 & 563.26 \\
& Simpson D & -0.19 & 0.28 & 0.28 & 563.34 \\
& Pielou J & -0.258 & 0.12 & 0.29 & 562.12 \\
& Funtional richness & -0.194 & 0.28 & 0.28 & 563.37 \\
& Functional divergence & -0.249 & 0.14 & 0.28 & 562.42 \\
Phylogenetic & Functional evennes & -0.248 & 0.13 & 0.29 & 562.23 \\
& RaoQ & $\mathbf{- 0 . 3 5 6}$ & $\mathbf{0 . 0 2 8}$ & $\mathbf{0 . 2 9}$ & $\mathbf{5 5 9 . 8 3}$ \\
& Phylo. spp. variability & 0.054 & 0.83 & 0.28 & 564.45 \\
& Phylo. spp. richness & -0.021 & 0.91 & 0.28 & 564.49 \\
& Phylo. spp. evenness & -0.226 & 0.2 & 0.29 & 562.9 \\
& Faith PD & -0.04 & 0.83 & 0.28 & 564.46 \\
& CWM.SLA & $\mathbf{- 0 . 4 2 6}$ & $\mathbf{0 . 0 1 4}$ & $\mathbf{0 . 3}$ & $\mathbf{5 5 8 . 6 6}$ \\
& CWM.height & -0.261 & 0.11 & 0.28 & 562.12 \\
& Ivy & $\mathbf{0 . 8 8 4}$ & $<\mathbf{1 0}$ & $\mathbf{0 . 3 7}$ & $\mathbf{5 4 5 . 5 3}$ \\
& Blackberry & -0.044 & 0.8 & 0.28 & 564.45 \\
\hline
\end{tabular}

This article is protected by copyright. All rights reserved. 
Table 3. Summary table of the multi-faceted model for the linear mixed-effect model (LMM) testing the relationship between biomass and several indices representing the four studied components of plant community structure including dominance (cf. the 'biomass-ratio hypothesis'), taxonomic diversity, functional diversity and phylogenetic diversity. Note that this LMM also includes confounding environmental variables as fixed effects with the windows variable (i.e., a factor variable with 9 levels) as a random intercept term. The $\mathrm{R}^{2}$ represent the total variance explained by both fixed and random factors (i.e. the entire model). Significant p-values $(<0.05)$ are in bold.

\begin{tabular}{llll}
\hline Indices & Parameter & Estimate & p-value \\
\hline \multirow{3}{*}{ Taxonomic } & Intercept & 7.582 & \\
Functional & Pielou J & 0.133 & 0.474 \\
Phylogenetic & RaoQ & -0.236 & 0.165 \\
Dominance & Phylo. spp. evenness & -0.185 & 0.265 \\
& CWM SLA & -0.165 & 0.349 \\
& Ivy & $\mathbf{0 . 7 7 6}$ & $\mathbf{0 . 0 0 1}$ \\
\hline Abiotic factors & Soil pH & 0.125 & 0.558 \\
& Available P & -0.008 & 0.96 \\
& Carbon:Nitrogen & 0.142 & 0.401 \\
& Canopy cover & -0.183 & 0.247 \\
& SCA & 0.098 & 0.539 \\
& MeanL & 0.079 & 0.677 \\
& MeanN & 0.3 & 0.161 \\
& MeanF & $\mathbf{0 . 3 6 8}$ & $\mathbf{0 . 0 3 8}$ \\
& Prop-grasslands & 0.008 & 0.967 \\
& Prop-croplands & 0.473 & 0.076 \\
& Edge-dist & 0.382 & 0.068 \\
\hline Model performance & AIC & 549.7 & \\
& R & 0.38 & \\
\hline
\end{tabular}

This article is protected by copyright. All rights reserved. 


\section{SUPPORTING INFORMATION}

Appendix S1: Variation in species' life-history traits over the phylogenetic tree of the 162 studied forest plant species occurring within our study area.

Appendix S2: Pearson's correlations among the 13 variables used to describe local environmental conditions.

Appendix S3: Pearson's correlations among all dominance/ diversity variables explored in this study (16 indices).

Appendix S4: Summary table of the linear mixed-effect model (LMM) testing the relationship between Ivy (Hedera helix. $L)$ and environmental drivers.

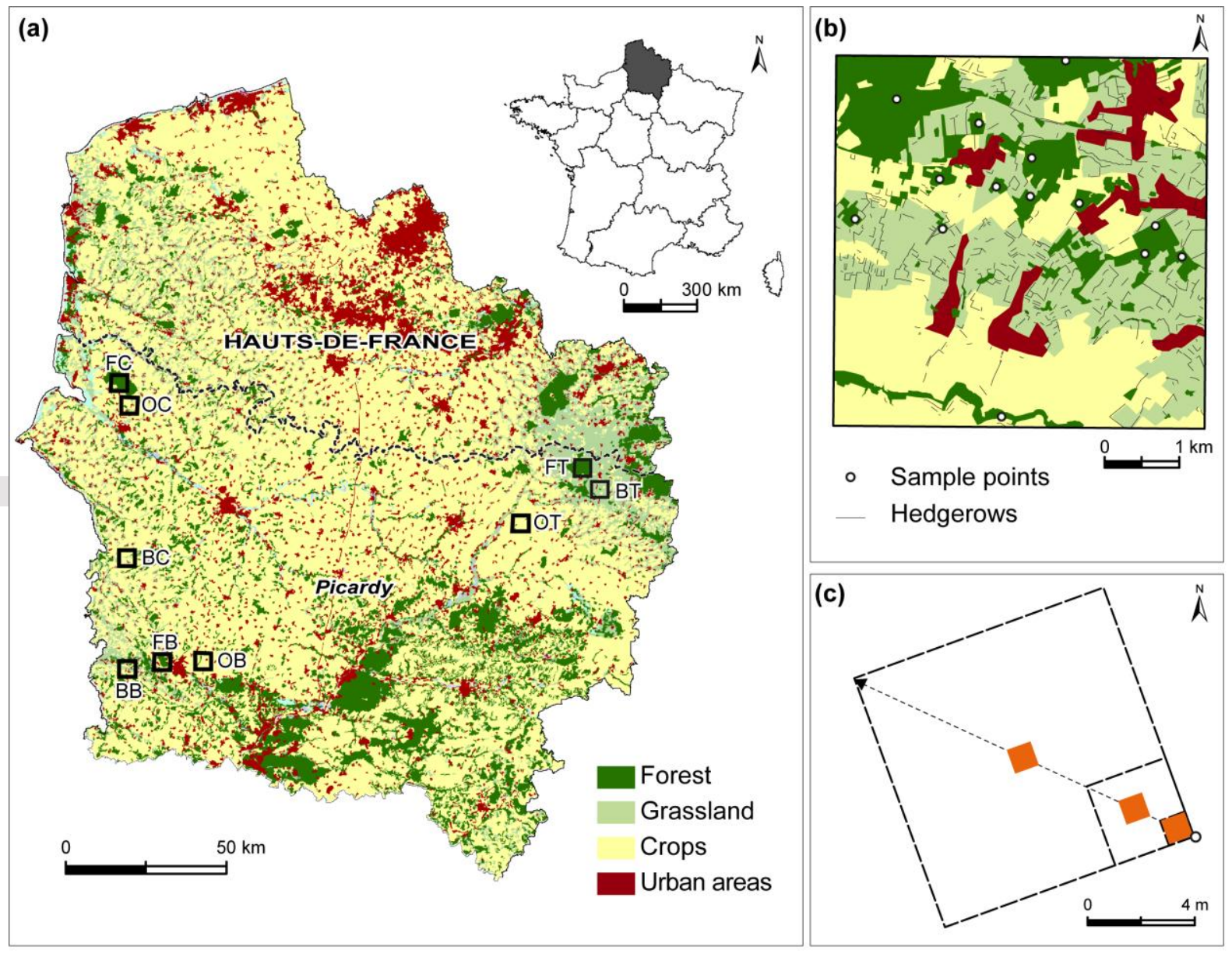

This article is protected by copyright. All rights reserved. 


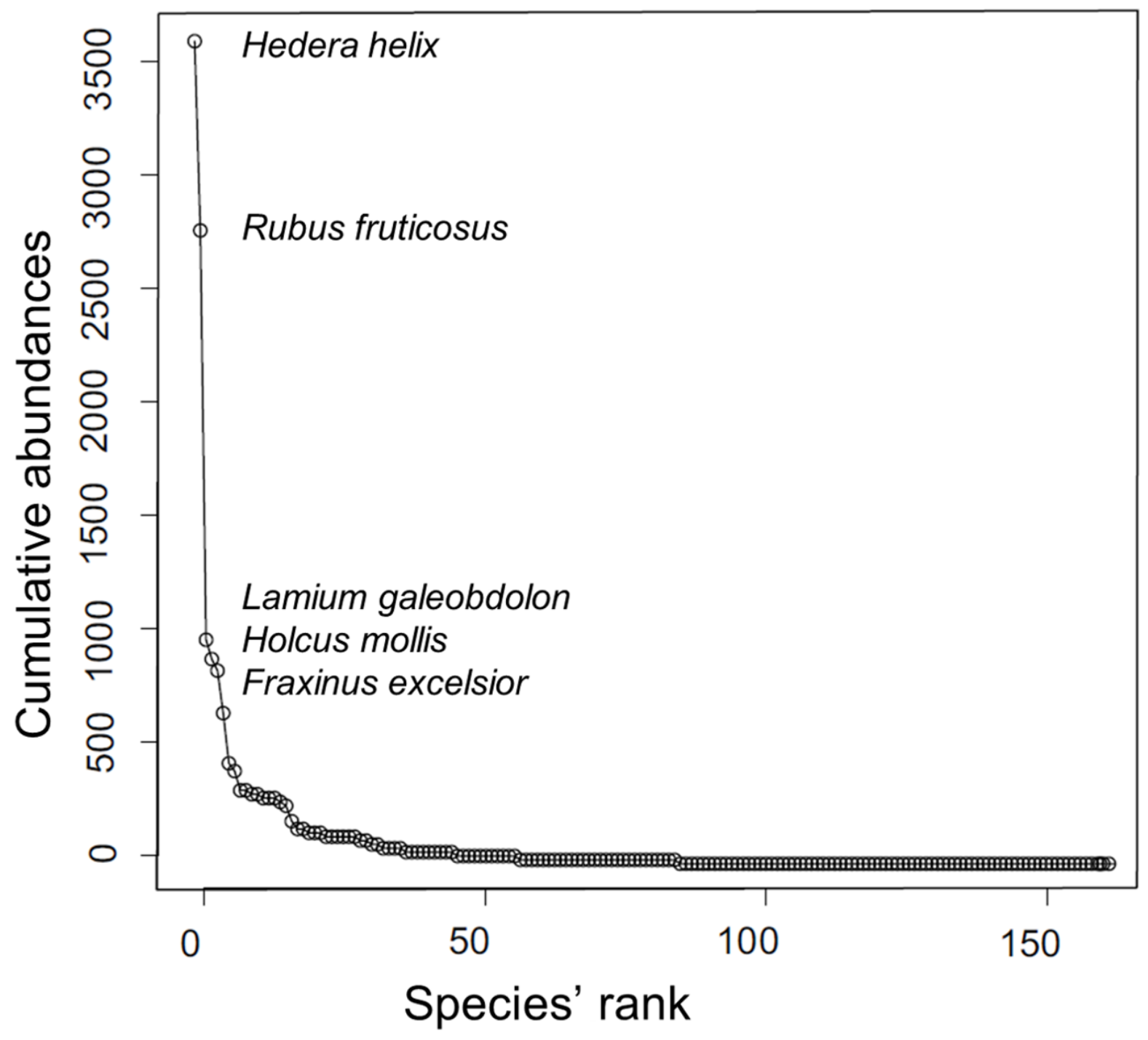

This article is protected by copyright. All rights reserved. 

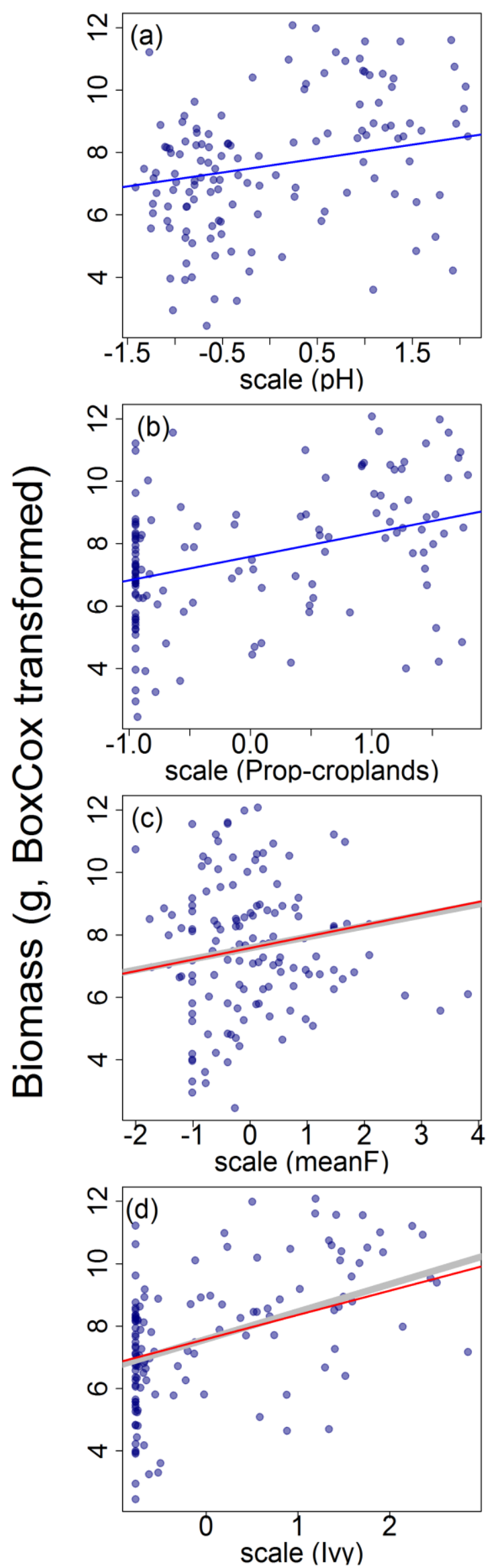

This article is protected by copyright. All rights reserved. 